\title{
Utilização dos conceitos de integração e segregação de fluxos da teoria de Análise de Cena Auditiva como ferramentas auxiliares no processo composicional
}

\author{
Use of the concepts of stream integration and segregation \\ from the theory of Auditory Scene Analysis \\ as auxiliary tools in the compositional process
}

\author{
Eduardo Fabricio Frigatti \\ Universidade de São Paulo \\ edufrigatti@yahoo.com.br
}

\section{Sílvio Ferraz}

Universidade de São Paulo

silvioferraz@usp.br

\section{Regis Rossi Alves Faria \\ Universidade de São Paulo \\ regis@usp.br}

Resumo: O presente trabalho versa sobre a utilização de conceitos da Teoria de Análise de Cena Auditiva no processo de criação da obra Quando as pedras tocam o espelho d'água de autoria de E. Frigatti. Nesta tarefa foram utilizadas concepções centrais sobre a organização e percepção de fluxos sonoros (sound streams), propostos pelo pesquisador de psicologia auditiva Albert Bregman, para a criação de uma polifonia de sonoridades: uma polifonia de fluxos sonoros. Descreve-se como dois dos princípios de segregação e integração sequencial de fluxos demonstrados por Bregman se tornaram ferramentas conceituais importantes neste processo composicional, conduzindo à camuflagem de um tema principal na peça - tomado emprestado do folclore musical brasileiro - ea sua posterior revelação progressiva. Apresentamos a seguir os resultados do experimento criativo, reflexões e apontamentos para futuras obras.

Palavras-chave: composição musical; estética da sonoridade; análise de cena auditiva; polifonia de fluxos sonoros.

Abstract: The present work is about the use of Auditory Scene Analysis theory concepts in the process of creating the musical piece Quando as pedras tocam o espelho d'água (When stones touch the 
water mirror) by E. Frigatti. In this task, we used central conceptions about the organization and perception of sound streams, proposed by auditory psychology researcher Albert Bregman, for the creation of a polyphony of sonorities: a polyphony of sound streams. It is described how two of the principles of stream segregation and sequential integration demonstrated by Bregman have become important conceptual tools in this compositional process, leading to the camouflage of a main theme in the piece - borrowed from the Brazilian musical folklore - and its subsequent progressive revelation. We present below the results of the creative experiment, reflections and notes for future works.

Keywords: music composition; aesthetics of sound; auditory scene analysis; poly phony of sound streams.

\section{1 - Sonoridade: o Som como Questão Central da Música e a Polifonia das Sonoridades}

Como observam diversos autores (Solomos, 2013; Guigue, 2011; Tenney, 1988), o século XX testemunhou a passagem de uma cultura de escuta musical centrada na nota para uma cultura centrada no som, aspecto observado na própria produção musical, isto é, na passagem da composição musical com sons à composição do som. O som - sua criação e transformação - tornou-se assim a problemática central da música. Como observa Tenney (1988, p. 7-8), “a substância e material desta música [do século $X X$ ] é o som - esta definição é inevitável - e é de importância secundária se este material está em forma de uma nota com altura claramente definida, ou de um som complexo de prato e com alturas indefinidas".

O musicólogo Didier Guigue, em seu livro "Estética da sonoridade: o legado debussysta aos compositores do século $X X^{\prime \prime}$, sob o ponto de vista desse novo paradigma estético, chama atenção aos processos polifônicos criados por Messiaen, em Regard du Père (movimento da obra Vingt regards sur l'Efant-Jésus), ao sobrepor dois grandes processos homogêneos que se desenvolvem paralelamente. $\mathrm{O}$ autor também discute os processos contrapontísticos de defasagens de ressonâncias criados por Luciano Berio na Sequenza IV para piano ${ }^{1}$, além de discutir as estratégias de compositores como George Crumb e Helmut Lachenmann, que aperfeiçoaram as modalidades de interação entre várias camadas de sonoridades produzidas por modos de atuação diferentes. Suas análises permitem observar que diferentes unidades sonoras ${ }^{2}$ - "[...] uma estrutura complexa gerada pela interação de vários componentes da escrita

\footnotetext{
${ }^{1}$ Como o próprio compositor italiano afirmou, as sequenzas são peças que fazem uso de técnicas contrapontísticas (Berio, 1988).

2 Observe que a definição se assemelha ao conceito de clang proposto por Tenney (1986, p. 86): um som ou configuração sonora que é percebida como unidade musical primária ou gestalt. Aliás, o próprio Guigue admite que seu conceito propõe uma reelaboração do modelo proposto por Tenney (Guigue 2011, p. 48-49).
} 
musical, cuja articulação é susceptível de suportar a forma, no todo ou em parte" (Guigue 2011, p. 49) - podem ser dispostas em uma oposição simultânea, criando várias camadas segregadas. Esse tipo de articulação das unidades sonoras, Guigue chamou de "polifonia de sonoridades" (Guigue 2011, p. 76-77).

De ponto de partida distinto, mas em concordância com Guigue, o compositor inglês Trevor Wishart discute como seria possível realizar uma escrita contrapontística do continuum sonoro. Wishart (1996, p. 116) destaca que “[...] para descrever uma experiência como contrapontística no sentido mais convencional, não é suficiente para nós a mera experiência da coexistência de um número de streams musicais". A noção de stream apresentada por Wishart reflete aquela de Bregman (1990, p. 44), que em seu livro Auditory Scene Analysis define streams - ou fluxos sonoros, numa tradução literal e adequadamente funcional para nossos propósitos - como representações perceptuais que fornecem centros de descrição que conectam características sensoriais de modo que certas combinações possam servir como base para reconhecer eventos ambientais. Do ponto de vista contrapontístico, esses fluxos sonoros devem ser sentidos como relacionados ou interagindo de algum modo durante o curso de seus desenvolvimentos, levando em conta, do ponto de vista arquitetônico, as transformações de um timbre ou área sonora em outra; e, do ponto de vista dinâmico, a evolução gestual e a interação entre os diferentes streams (Wishart 1996, p. 116).

A partir dessa observação, Wishart desenvolve seis modelos para a organização vertical dos gestos que nos são aqui pertinentes para pensarmos o processo composicional: (1) completamente paralelo; (2) semiparalelo, em que as partes seguem a mesma lógica gestual mas não de modo sincrônico; (3) independência homogênea, quando gestos homogêneos se comportam de modo independente; (4) independência heterogênea, quando os gestos são heterogêneos e independentes; (5) interativa, em que eventos de um fluxo influenciam outro; (6) gatilho, um gesto dispara um evento em outro fluxo (Wishart 1996, p. 121-122).

Deve-se ressaltar que um fluxo pode ser resultado de vários eventos horizontais concomitantes, gerando um único fluxo, uma única textura. A partir da leitura realizada por Eimert (1961) em sua análise da obra Jeux de Debussy, Ferraz (1991) observa que a textura sonora, embora sempre conhecida pelos compositores, só se tornou relevante como fundamento composicional através de Debussy, uma iniciativa aparentemente isolada que só foi considerada importante pelas correntes historicistas do pensamento musical em 1960, quando retomada por integrantes da Escola de Darmstadt. Ainda segundo Ferraz (1991), “[n]a retomada de Debussy já na metade do século XX por K. Stockhausen ${ }^{3} \mathrm{e}$

3 Vide Maconie, 2009. 
posteriormente por György Ligeti, [...] os resultados texturais deixaram de ser perseguidos para descrever gestos extra-musicais, mas para estruturar o próprio discurso intra-musical, enfatizando transformações sonoras, desenvolvimentos do complexo sonoro, enfatizando a própria textura da peça".

\section{2 - Análise de Cena Auditiva}

O conceito de Auditory Scene Analisys (ASA) - ou, em tradução literal, Análise de Cena Auditiva - elaborado e disseminado pelo doutor em psicologia e pesquisador da percepção auditiva Albert Bregman, trata do processo pelo qual todas as evidências auditivas que chegam, ao longo do tempo, a partir de uma única fonte ambiental, são colocadas juntas em uma unidade perceptiva (Bregman 1993, p. 11).

Em largo espectro, os conceitos e princípios da $A S A$, desenvolvidos a partir de uma série de pesquisas experimentais desde a década de 1960, remetem à questão da percepção da fusão ou separação de elementos de um todo. Bregman (2008) define $A S A$ como "um processo em que o sistema auditivo toma a mistura do som derivada de um ambiente complexo e a desmembra em pacotes de evidências acústicas em que cada pacote provavelmente surge a partir de uma única fonte de som". Este agrupamento basal ajudaria o reconhecimento de padrões para não misturar informação de diferentes fontes.

$\mathrm{Na}$ música, entretanto, as evidências acústicas tendem a formar agrupamentos que intencionalmente derivam de muitas fontes sonoras ao mesmo tempo, e muitas vezes só são percebidos graças à atuação conjunta de fontes distintas. Como aponta Pressnitzer (2011), "curiosamente, os músicos nem sempre pretendem tornar cada fonte física inteligível, mas sim expressar uma ou mais linhas melódicas com um pequeno ou grande número de instrumentos".

Segundo Bregman (2008), há pelo menos duas dimensões a considerar no agrupamento perceptual sonoro. O primeiro é sequencial, em que "bits" de dados auditivos são conectados ao longo tempo, como numa melodia. E o segundo é simultâneo, no que "bits" de dados chegando ao ouvido ao mesmo tempo são integrados ou segregados uns dos outros em fluxos distintos pelo processamento auditivo. Um exemplo deste segundo ocorre com os acordes, o conhecimento de três ou mais notas como uma entidade separada.

Bregman apresenta diversas conceituações úteis à reflexão sobre os processos musicais criativos e a escuta. A seguir, apresentamos as principais formulações que utilizamos de sua teoria. Em seus estudos, Bregman observa que junto a esquemas aprendidos, que podem ser acionados involuntária ou voluntariamente, existem métodos para particionar uma amálgama de som em fontes acústicas separadas que poderiam ser usadas antes de qualquer 
conhecimento específico dos sons importantes do ambiente (Bregman 1993, p.13). Esses métodos, aos quais ele dedica a maior parte de sua investigação (Bregman 1990, p. 641), são referenciados como primitive scene analisys.

De acordo com ele, esse processo primitivo de análise dos eventos sonoros se vale da regularidade dos estímulos para organização perceptual (Bregman 1993, p. 15-16). Em síntese, tais regularidades estão associadas a fatos acústicos como (Bregman 1993, p. 17-30):

- Sons não relacionados raramente começam e terminam exatamente ao mesmo tempo.

- Gradações de mudança são percebidas como regulares quando: a) um som único tende a mudar suas propriedades suave e lentamente; b) uma sequência de sons de uma mesma fonte tende a mudar suas propriedades lentamente.

- Quando um corpo vibra com um período repetitivo, suas vibrações dão origem a um padrão acústico no qual os componentes frequenciais são múltiplos de uma fundamental comum ${ }^{4}$.

- Muitas mudanças que ocorrem em um evento acústico afetarão todos os componentes do som resultante de um mesmo modo ao mesmo tempo.

Além dos processos 'primitivos', que diz serem inatos, Bregman discorre também sobre aqueles baseados em esquema (schema-based), que estão relacionados e são perceptíveis (e enfatizados) a partir do aprendizado. Embora este último não seja o foco de sua pesquisa, o autor expõe algumas reflexões a respeito, atentando para o fato de tais esquemas envolverem o controle aprendido da atenção. $\mathrm{O}$ aprendizado baseia-se na exposição do indivíduo a certos padrões de seu ambiente, como no caso da fala e da música (Bregman 1993, p. 38-43).

\section{3 - O processo de criação}

Ao longo de 2017 nos dedicamos ao trabalho composicional de Quando as pedras tocam o espelho d'água para três clarinetes e clarinete baixo, encomendado pelo Quarteto de Clarinetes da Universidade de São Paulo (USP), coordenado pelo professor Dr. Luís Afonso "Montanha". A peça foi estreada pelo referido grupo ainda naquele mesmo ano, em concerto realizado na Universidade de São

\footnotetext{
4 Neste sentido constata-se um cenário escassamente explorado com relação aos sons inarmônicos.

${ }^{5}$ Partitura completa disponível no link:

https://drive.google.com/open?id=1N6AFfd501RpvZTsj2OMaia6IkD0RbEgW
} 
Paulo. O mote para composição da obra surgiu a partir de uma das aulas da disciplina de "Processamento de Sinais Musicais", do Programa de PósGraduação em Música da USP, na qual o docente responsável explanava sobre a teoria de $A S A$, de Albert Bregman.

Após a leitura e audição de alguns experimentos propostos por Bregman (2008), os alunos realizaram um trabalho em que deveriam reproduzir ou criar novos experimentos relativos a esta teoria. A partir dessa ideia, compôs-se a peça durante a disciplina de "Criação e Performance em Música Contemporânea", também do Programa de Pós-Graduação em Música da USP.

Embora possam se relacionar mais conceitos, fundamentalmente foram utilizados para elaboração da peça os princípios de segregação e integração sequencial de fluxos ${ }^{6}$ que conduzem:

(1) ao reconhecimento de padrões, distribuídos dentro de ou entre fluxos perceptivos; e

(2) à separação de melodia a partir de notas (tons) interferentes.

O ponto inicial do processo composicional parte do conceito 2, que resultou na segunda seção da obra. Em seguida, a aplicação do conceito 1 conduziu à criação da primeira seção da obra.

Na primeira seção da peça, utilizou-se o conceito de organização de padrões dentro e entre fluxos perceptivos, o que influenciará no reconhecimen to dos mesmos, e que Bregman demonstra como um efeito de camuflagem. Segundo ele, a organização perceptiva normalmente ajuda o reconhecimento de padrões ao agrupar os componentes acústicos que são suscetíveis de fazer parte do mesmo padrão significativo. No entanto, no exemplo abaixo, ilustrado na Figura 1, Bregman demonstra uma ruptura dos padrões significativos, gerando agrupamentos inapropriados (Bregman 1990, p. 50; 138-140; 147; 153).

\begin{abstract}
Nesta demonstração, o subconjunto que você deve escutar é apresentado primeiro como um padrão, um ciclo repetitivo de três tons (lado esquerdo dos painéis 1 e 2). O ciclo completo de seis notas é tocado logo depois (lado direito dos painéis). A figura mostra a última parte do padrão seguido pelo início do ciclo completo.

Na primeira parte da demonstração, o padrão é escolhido para que quando o ciclo completo se romper em fluxos, os três tons do padrão sejam deixados em um único fluxo (Painel 1, quadrados pretos). Portanto, esse tipo, chamado de "padrão dentro do stream", é fácil de ouvir como uma parte distinta dentro do ciclo completo (grifo nosso).

Na segunda parte, o padrão é escolhido para que, quando o ciclo se romper em fluxos, duas das notas do padrão sejam deixadas em um fluxo e a terceira nota
\end{abstract}

\footnotetext{
6 Vide mais detalhes sobre todos os princípios nas demonstrações disponíveis no sítio do Laboratório de Pesquisa de Análise de Cena Auditiva da Universidade McGill, Canadá: http://webpages.mcgill.ca/staff/Group2/abregm1/w eb/downloadstoc.htm\#toc
} 
no outro fluxo (consulte o Painel 2, quadrados pretos). Esse tipo, chamado de "padrão em fluxo contínuo", é muito difícil de detectar no ciclo de seis tons (grifo nosso). (Bregman, 1996 apud Bregman, 2008)

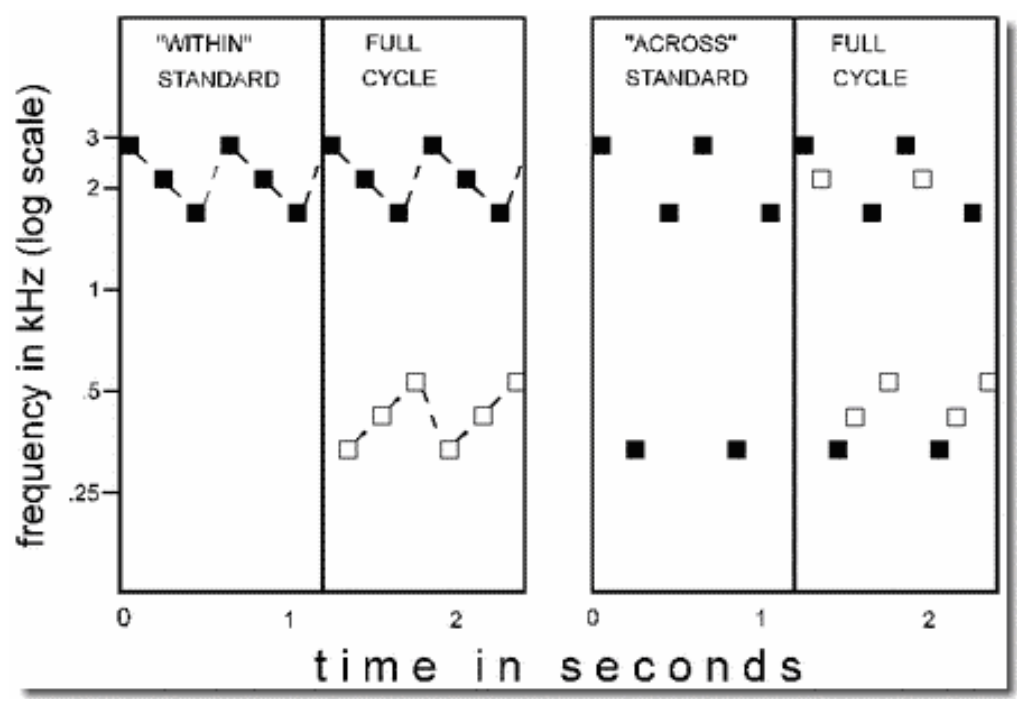

Figura 1: Reconhecimento de padrões, dentro e entre fluxos perceptivos (cf. Bregman, 2008)

Na demonstração auditiva de Bregman, que é possível ouvir no sítio na internet (Bregman, 2008), fica claro que o deslocamento de um componente do padrão no eixo das alturas, quando mantido seu sequenciamento temporal, provoca uma segregação na percepção do padrão devido à integração das notas em fluxos distintos quando o padrão é executado em ciclos. O reconhecimento do padrão se torna então (mais) difícil.

A primeira seção da peça foi elaborada a partir dessa concepção de 'camuflagem'. Cada clarinete tem sua própria linha melódica. Essas linhas melódicas são elaborações a partir do tema principal transformado (que será apresentado logo a seguir). Portanto, as linhas melódicas compartilham estruturas e motivos semelhantes. As entradas das linhas são em estilo fugato, ocasionando inicialmente certa independência. Contudo, essas linhas são repetidas diversas vezes, com pequenas variações de andamento e dinâmica. Assim, após a entrada de cada instrumento, as vozes começam a se misturar, gerando novos padrões melódicos. Tais padrões são resultantes da formação de "agrupamentos inapropriados", pois os padrões incrustam-se um sobre o outro no transcorrer da seção, dificultando ao ouvinte seguir cada voz separadamente. Nesta situação, os padrões de cada linha melódica são quebrados entre fluxos distintos, e o padrão é camuflado. 
No Exemplo 1 mostra-se o início da peça até a entrada do clarinete, trecho que pode ser ouvido online e que demonstra a ocorrência (da percepção) de agrupamentos não relacionados à linha melódica de cada clarinete.

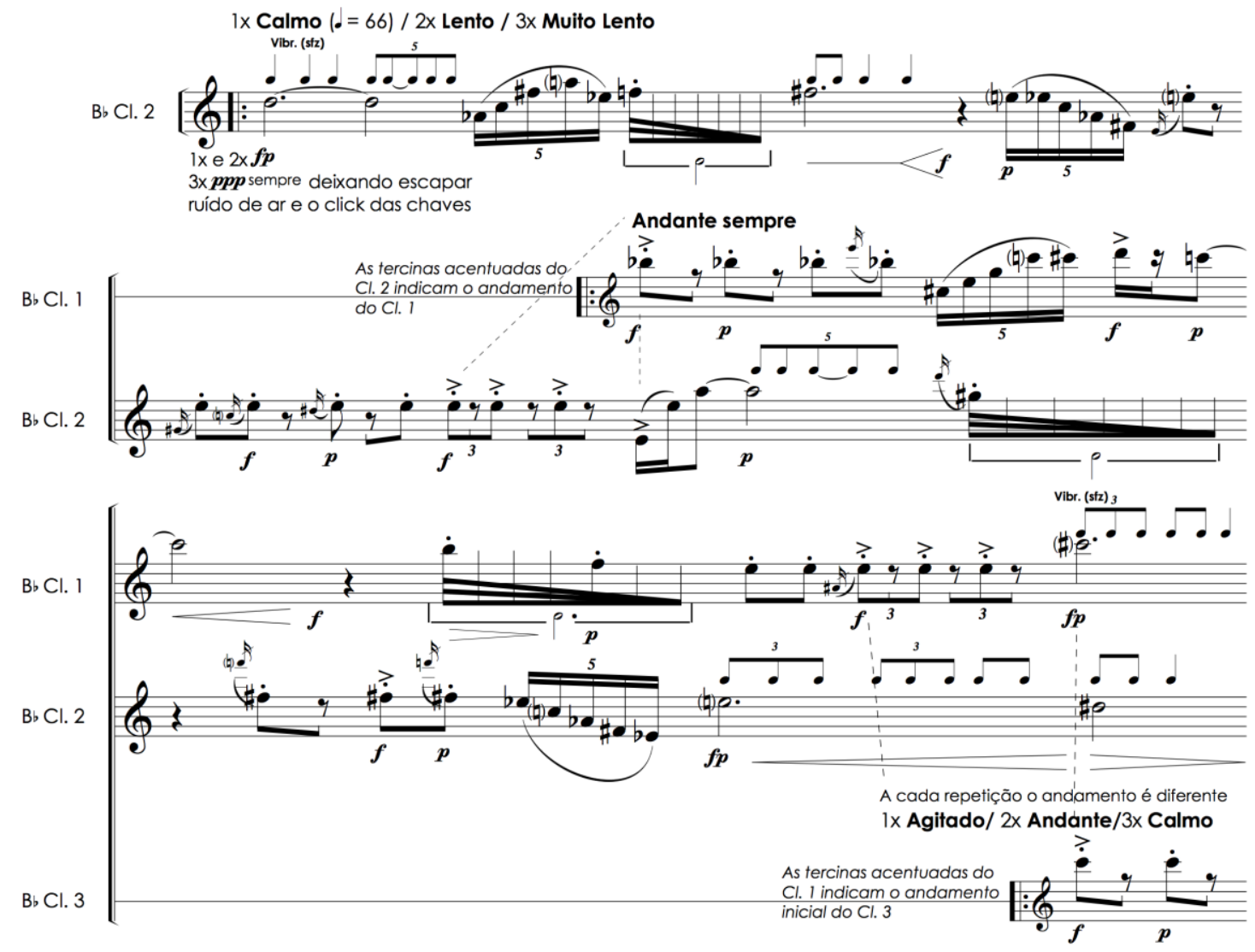

Exemplo 1: Início da peça até a entrada do terceiro clarinete ${ }^{7}$. Vozes na mesma tessitura misturam-se umas às outras, induzindo à percepção de agrupamentos imprevisíveis.

Na segunda seção da obra recriou-se o experimento de segregação de melodias a partir de notas interferentes (Figura 2). Em tal experimento uma melodia é executada intercalada por notas que formam o acompanhamento. Quando as notas estão na mesma região, com o mesmo timbre e mesma intensidade, elas formam um único fluxo sonoro, impossibilitando $o$ reconhecimento da melodia. Contudo, a partir da separação paulatina da tessitura através da transposição da melodia, esta se torna mais evidente (vide Bregman 1990, p. 61-64, 140, 462-466). Observou-se que, se a melodia pertencer ao repertório do ouvinte, o processo de segregação é facilitado. Por isso, no experimento realizado, que se tornou ponto de partida para a composição, foi usada como tema principal a canção Peixe Vivo do repertório popular brasileiro.

${ }^{7} \mathrm{O}$ áudio de uma gravação do trecho inicial está disponível no link https://drive.google.com/open?id=15SQDI_97bFjU5wVVkfzij2kR3f69_zp6C

\section{MUSICA THEORICA}

Revista da Associação Brasileira de Teoria e Análise Musical Journal of the Brazilian Society for Music Theory and Analysis @ TeMA 2017 - ISSN 2525-5541 


\section{I SMTERLAOCDTYO R S}

Figura 2: Ilustração gráfica sugerindo a separação de um padrão (melodia) a partir de notas interferentes ${ }^{8}$ ou distratoras (cf. Bregman, 2008)

Como mencionado anteriormente, a segunda seção da peça foi elaborada a partir de um trabalho didático/experimental sobre processamento de sinais musicais baseado no conceito de mascaramento. Esta seção, que se inicia no compasso 26 (Movimentado), trata-se de um grande hoqueto ${ }^{9}$ em que primeiro se apresenta o acompanhamento (Exemplo 2). Trata-se de uma série ${ }^{10}$ em que cada instrumento toca uma nota.

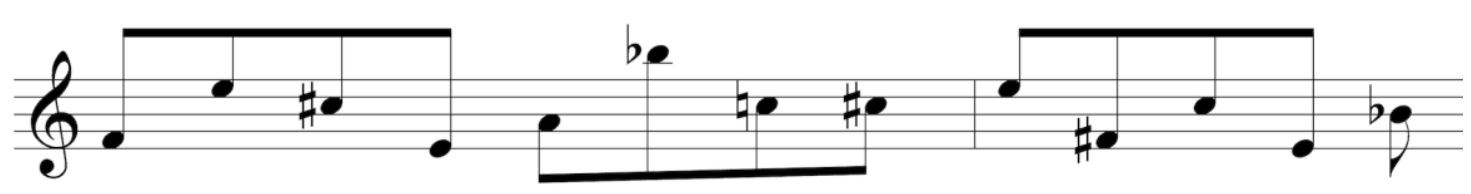

Exemplo 2: Acompanhamento original, reduzido a uma única voz

Após algumas repetições, o acompanhamento passa por um processo de compressão intervalar ${ }^{11}$, i. e., a cada repetição a distância entre os saltos diminui um semitom. Este procedimento é repetido até chegar à mínima compressão possível: repetição da nota Dó sustenido (aproximadamente a partir do comp. 77). Pouco antes de chegar a esta mínima compressão, o tema do Peixe Vivo surge pela primeira vez (comp. 72). Neste momento, o acompanhamento, que já difere muito de sua primeira aparição, apresenta-se como exemplifica do no Exemplo 3. Por estarem na mesma região e com o mesmo timbre, o tema é mascarado pelo acompanhamento (Exemplo 5, discutido a seguir).

\footnotetext{
${ }^{8}$ Vide: http://w ebpages.mcgill.ca/staff/Group2/abregm1/w eb/downloadstoc.htm\#toc

9 Técnica de composição típica do período medieval, na qual se reparte a melodia entre as diversas vozes. Interrompe-se o fluir da melodia em uma única voz através da inserção de pausas, de modo que as notas ausentes sejam cantadas por outra voz.

10 Sequência fixa de notas.

${ }^{11}$ Esta técnica deriva da técnica de projeções proporcionais do compositor Flô Menezes. Segundo o compositor, esta técnica surgiu da ideia de criar projeção de entidades (ou modos cíclicos) em espaços harmônicos distintos, ou seja, ocupando registros diversos de seu registro original, porém preservando sua proporcionalidade intervalar e, portanto, sua identidade. As projeções perfazem ambos os sentidos: ora comprimir, ora estender as entidades no âmbito das alturas (Menezes 2013, p. 98).
}

\section{MUSICA THEORICA}




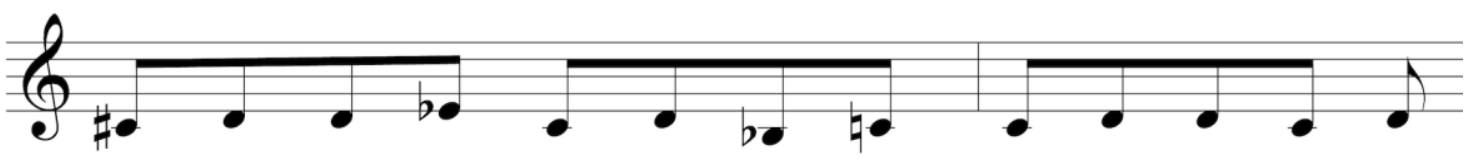

Exemplo 3: Exemplo de compressão intervalar do acompanhamento

Para a construção da melodia utilizou-se somente a primeira parte do tema da canção Peixe Vivo. Assim como o acompanhamento, a melodia passa por um processo de alteração intervalar, tornando o tema mais cromático e menos reconhecível. Dessa forma, na primeira vez que o tema aparece (comp. 72), ele encontra-se alterado, e a cada repetição ele se torna mais próximo do original. As suas duas últimas aparições já expõem sua relação intervalar original (vide Exemplo 4).

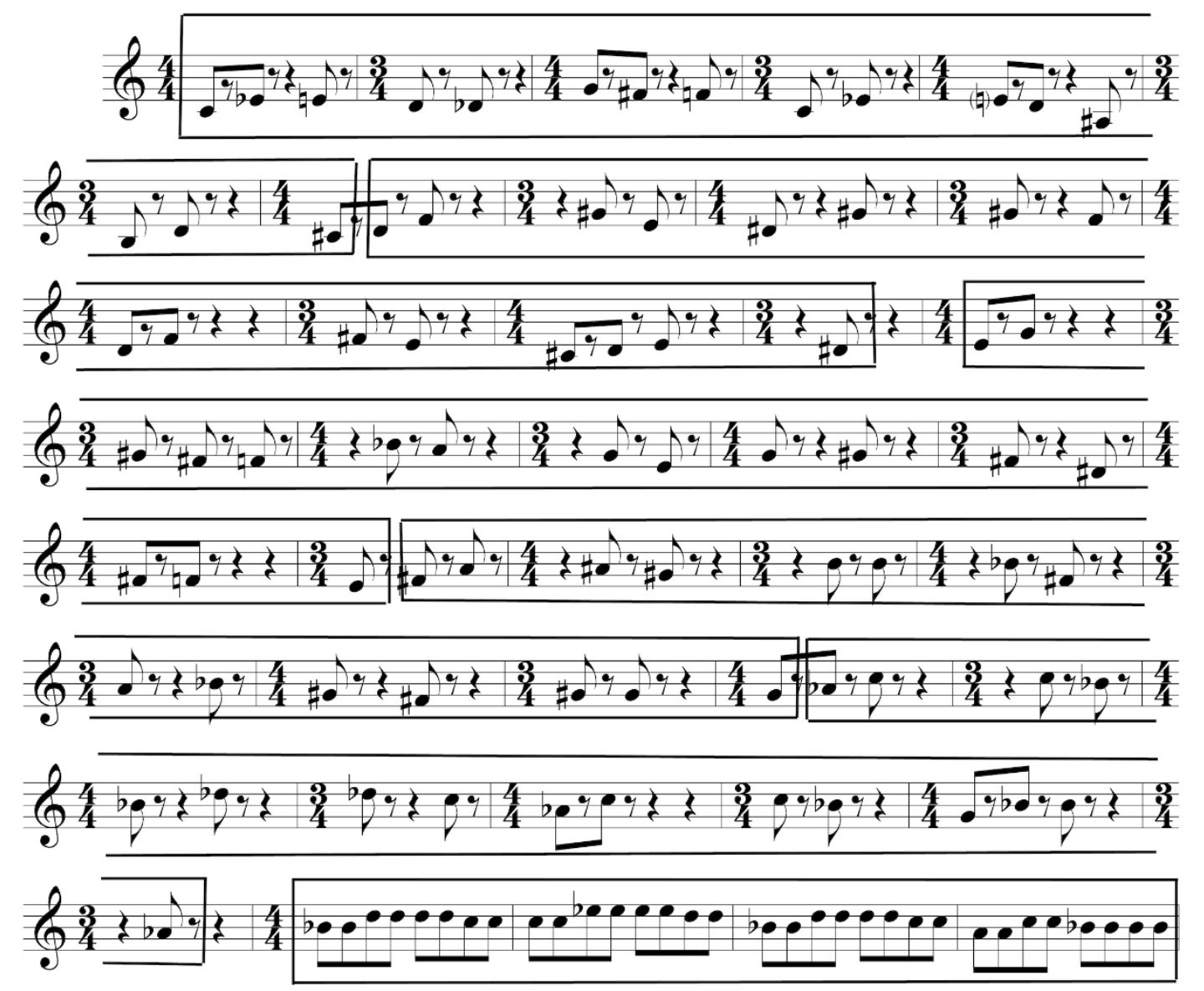

Exemplo 4: Exemplo do tema reduzido a uma única voz. Cada retângulo trata de uma transformação do tema Peixe Vivo e indica uma nova entrada do mesmo. A cada repetição as alterações cromáticas diminuem, revelando progressivamente o tema ${ }^{12}$. $\mathrm{O}$ tema já é claro na penúltima entrada (Láb), e aparece dobrado na última (Sib)

12 Áudio a partir da entrada da melodia até o final da peça disponível no link: https://drive.google.com/open?id=1OWm7ThOrH3BJoOT3alR8EgUpPxeImXhw 
Além disso, para desconstruir o mascaramento, isto é, para revelar a forma, a melodia é transposta um tom acima a cada repetição, enquanto a tessitura do acompanhamento vai se tornando também mais grave (Exemplo 5).

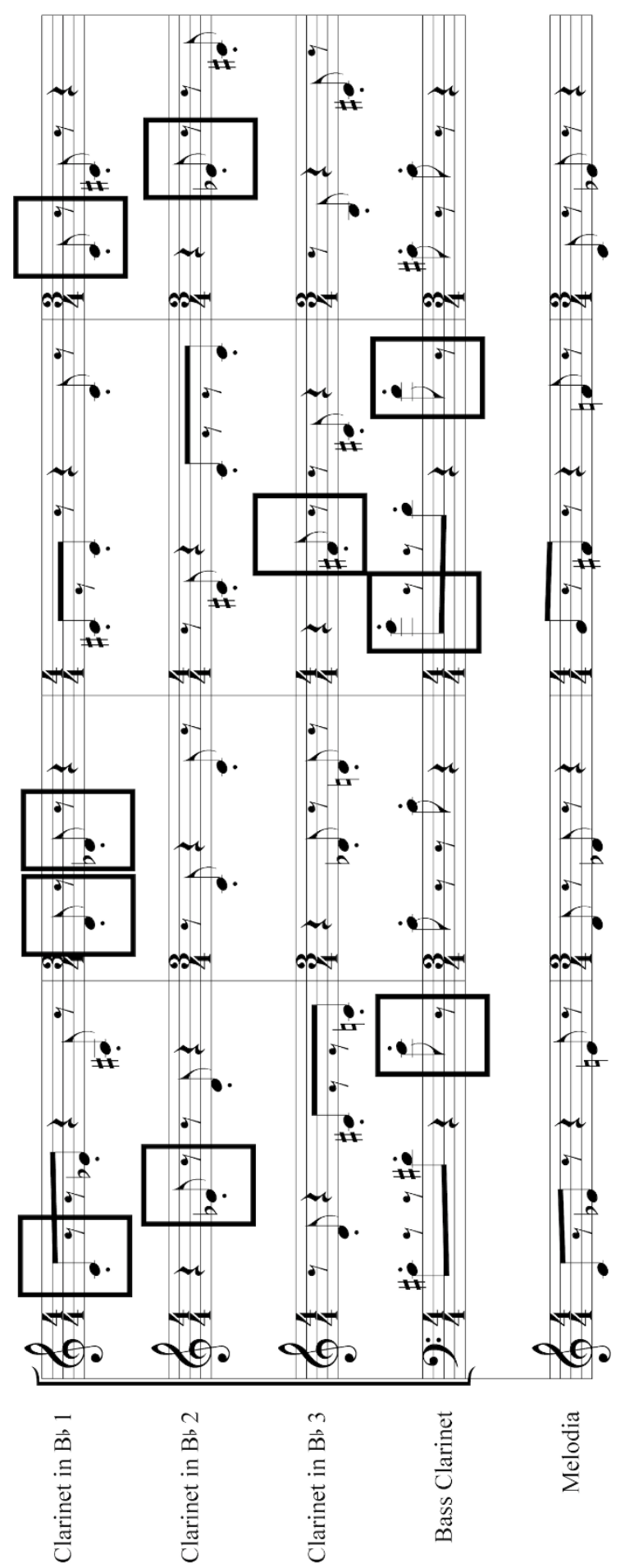

Exemplo 5: Primeira entrada do tema transformado (comp. 72-75), sem transposição do instrumento (i.e., transcrito 1 tom abaixo, na altura real). Como explicado no texto, o tema está misturado ao pedal de Dó\#/Réb. 
Durante a maior parte da seção (aproximadamente entre os compassos 72 e 93), a melodia é distribuída entre os quatro clarinetes. Contudo, a partir da segregação dos fluxos, ela passa paulatinamente a ser executada por três, dois e um clarinete respectivamente (Exemplo 6).

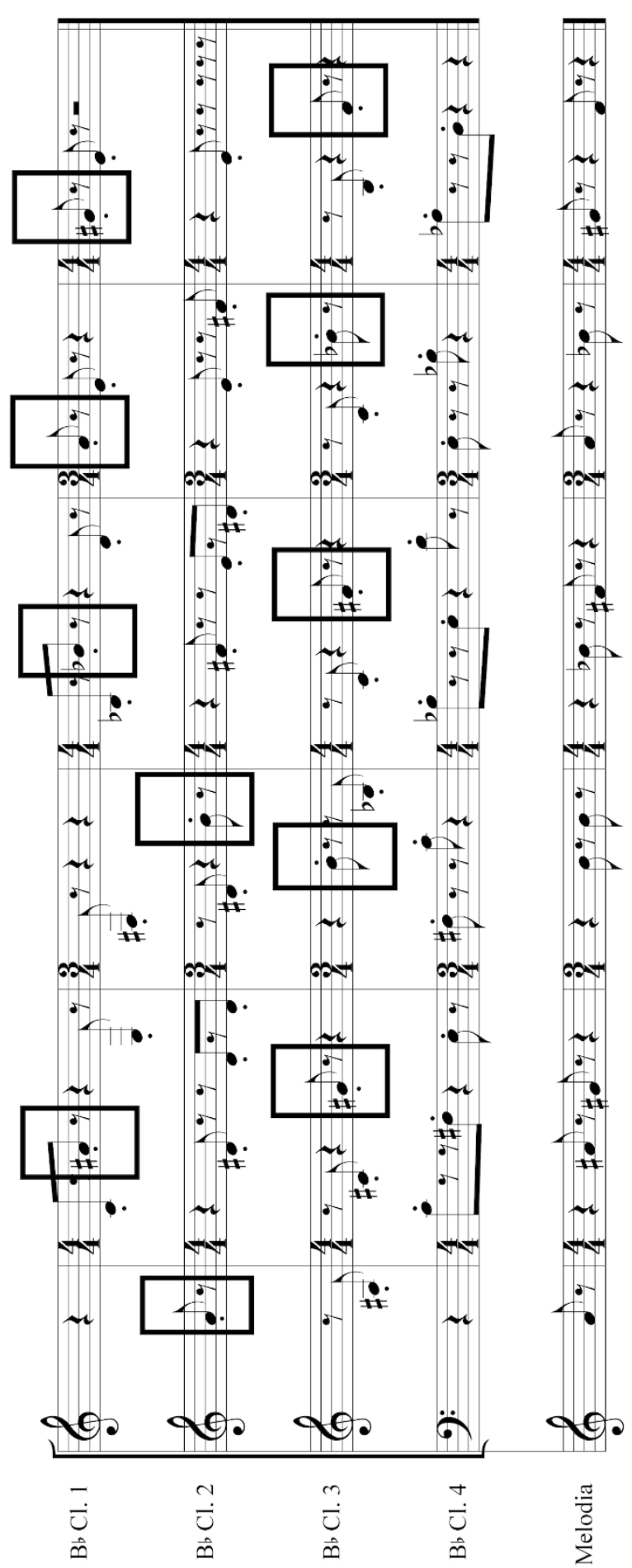

Exemplo 6: Trecho do comp. 94-98. Exem plo da distribuição das notas da melodia entre os instrumentos, sem transposição do instrumento (notado 1 tom abaixo, na altura real). 
Assim, a melodia que estava dividida entre os quatro clarinetes passa, progressivamente, a concentrar-se em um único instrumento, uma única fonte ambiental.

\section{4 - Conclusões}

O pensamento polifônico adquire novas possibilidades ao ser entendido enquanto ordenamento de fluxos sonoros, ou polifonia de fluxos sonoros. Sob essa perspectiva, a teoria de Bregman, que versa sobre a análise de cenas auditivas, apresenta-se como interessante ferramenta para refletir sobre procedimentos composicionais já existentes, assim como inferir novas estratégias de criação.

Como exposto, demonstrou-se a aplicabilidade dos conceitos de análise de cena auditiva no processo composicional de uma obra musical. Assim, na primeira seção da peça os ostinatos se confundem através dos agrupamentos 'inapropriados', criando uma única textura em que alguns elementos melódicos escapam. Tais elementos sempre variam. Na segunda seção, realizou-se a separação de um fluxo em dois (Exemplo 6): o acompanhamento (um fluxo sonoro) e a melodia (outro fluxo sonoro). Inicialmente, encontram-se em um único fluxo, uma vez que estão ocupando a mesma tessitura e não há outro fator (que não a altura) para prover segregação. Posteriormente, aos poucos, a melodia se segrega do acompanhamento, possibilitando a percepção de dois fluxos sonoros.

$\mathrm{O}$ fato de o timbre das vozes ser o mesmo (clarinetes) aprofunda a percepção da camuflagem desejada na peça. Bregman $(1996,2008)$ denota este aspecto ao ressaltar que fatores acústicos como o mesmo timbre (conteúdo espectral semelhante) influenciam a integração simultânea de componentes em um fluxo, enquanto timbres diferentes facilitariam a segregação de fluxos. Acredita-se que o fator de aprendizado (no caso cultural) pode intensificar o processo de segregação entre tais fluxos sonoros, pois se trata de uma melodia popular da música folclórica brasileira. Em geral, notamos que um segredo central por trás de $A S A$ está na manipulação do andamento e transposição de elementos, que possibilitam a evidência ou oclusão de streams, bem como sua aparição e desaparecimento por meio de fusões e segregações de componentes, processos usuais na música, mas retratados sob outro ponto de vista.

Como mencionado, a peça foi estreada pouco após sua composição. Durante os ensaios, observou-se que o andamento deve ser preciso para que se alcance o resultado esperado. Observou-se também que a execução do hoqueto 
não é simples, no entanto, quando alcançada é possível perceber a melodia mesmo não estando concentrada em nenhum dos instrumentos ${ }^{13}$.

A teoria da análise de cena auditiva abriu fronteiras importantes para o estudo da percepção e cognição musical. Por exemplo, a compreensão de como o agrupamento perceptual de sons musicais é mediado pelo sistema auditivo tem sido objeto de investigação de modelos computacionais para desvendar como o agrupamento de sons se dá através do tempo, de acordo com seus timbres, brilho e sincronia de início (Brown e Cooke, 2008). Alguns pesquisadores consideram que a música possa ter surgido inicialmente como uma criação cultural possibilitada por adaptações de características preexistentes do processamento auditivo (ex: percepção da altura e da estrutura temporal) que evoluíram então para um complexo sistema de análise de cena acústica ou cena auditiva (Trainor, 2015).

Ao demonstrar a abstração de heurísticas úteis como ferramentas composicionais a partir de dois princípios de segregação e integração de fluxos sonoros extraídos da teoria de Análise de Cena Auditiva, acredita-se que outras ferramentas possam também descender dos conceitos e mecanismos funcionais documentados em outros 23 casos de segregação e integração sequencial e simultâneas abordados por Bregman (1996) e acessíveis online em Bregman (2008). A exploração destes é objeto de um vasto campo aberto à investigação futura.

\section{Agradecimentos}

Os autores agradecem ao Quarteto de Clarinetes da Universidade de São Paulo (USP), coordenado pelo professor "Montanha", e ao apoio do CNPq, processo no 313481/2017-2.

\footnotetext{
${ }^{13}$ Isto torna-se notável por consideramos que a fonte ambiental não é única mais, mas um conjunto de fontes de mesmo timbre, tecnicamente extrapolando o escopo originalmente previsto por Bregman (1993, p. 11).
} 


\section{Referências}

1. Bregman, Albert S. 1990. Auditory Scene Analysis: the Perceptual Organization of Sound. Cambridge: The MIT Press.

2. 1993. Auditory Scene Analysis: Hearing in Complex Environments. In: Thinking in Sound: the Cognitive Psychology of Human Audition, p. 10-36. S. McAdams e E. Bigand (Eds.). Oxford: Oxford University Press.

3. Bregman, Albert S.; Ahad, P. 1996. Demonstrations of Auditory Scene Analysis: The Perceptual Organization of Sound. Audio Compact Disk. McGill Auditory Perception Laboratory \& MIT Press. Disponível em:

<http://webpages.mcgill.ca/staff/Group2/abregm1/web/downloadsdl.htm> Acesso em 18 nov 2017.

4. Bregman, Albert S. 2008. Audio Demonstrations of Auditory Scene Analysis. In: Al Bregman's Website. McGill University. Disponível em: $<$ http://webpages.mcgill.ca/staff/Group2/abregm1/web/downloadsintro.htm>. Acesso em 18 nov 2017.

5. Brown, Guy J.; Cooke, Martin. 1994. Perceptual Grouping of Musical Sounds: A Computational Model. Journal of New Music Research, v. 23, no 2, p. 107-132.

6. Eimert, Herbert. 1961. Debussy's Jeux. Leo Black (trad.). Die Reihe 5, p. 3-20.

7. Ferraz, Silvio. 1990. Análise e Percepção Textural: a Peça VII de Dez Peças para Quinteto de Sopros de G. Ligeti. In: Cadernos de Estudo: Análise Musical, no 3, p. 78-79. São Paulo: Através.

8. Guigue, Didier. 2011. Estética da Sonoridade: a Herança de Debussy na Música para Piano do Século XX. São Paulo: Perspectiva.

9. Maconie, Robin. 2009. Stockhausen sobre A Música: Palestras e Entrevistas Compiladas por Robin Maconie. Saulo Alencastre (trad). São Paulo: Madras.

10. Menezes, Flô. 2013. Matemática dos Afetos: Tratado de (Re)composição Musical. São Paulo: Editora da Universidade de São Paulo.

11. Pressnitzer, Daniel; Suied, Clara; Shamma, Shihab. 2011. Auditory Scene Analysis: the Sweet Music of Ambiguity. Frontiers in Human Neuroscience, v. 5, p. 158. 
12. Solomos, Makis. 2013. De la Musique au Son: L'Émergence du Son dans la Musique des XX e XXIème Siècles. Rennes: Aesthetica.

13. Tenney, James. 1988. Meta-hodos and Meta Meta-hodos. Oakland: Frog Peak Music.

14. Trainor, Laurel J. 2015. The Origins of Music in Auditory Scene Analysis and the Roles of Evolution and Culture in Musical Creation. Phil. Trans. R. Soc. B, v. 370, o 1664, p. 20140089.

15. Wishart, Trevor. 1996. On Sonic Art. Amsterdam: Harwood Academic Publishers $\mathrm{GmbH}$. 